\title{
Filgueira Valverde en zapatillas
}

\author{
Ángeles Filgueira IgLesias
}

Galicia é a fala. A lingua é a testemuña da nosa personalidade, a lectura requinta a nosa fala e, porén, perpetúanos como pobo

Xosé Filgueira Valverde

Muchas gracias por invitarme a participar en este acto*, para mí tan emotivo. Hablar del padre ausente y tan querido debería serme fácil por el contacto directo y lo muy querida que me sentí. Carmen Mejía Ruiz me pidió que hablara de cosas personales, que la parte intelectual de este encuentro la cubría Lidia López Teijeiro, profesora de lengua gallega en el CEG de la Universidad Complutense.

Soy la quinta de cinco hermanos, la que se quedó en casa cuando los demás se fueron a estudiar a la universidad. Más tarde, la que le acompañaba cuando venía a Madrid a las Reales Academias, a las Cortes o a dar conferencias.

La nuestra era una casa muy grande llena libros por todas partes; en algún rincón quedaba espacio libre. La casa está en Pontevedra, con entrada por Arzobispo Malvar, una calle amplia, y la parte posterior daba al río Lérez del que nos separaba nuestro jardín grande y la carretera. Teníamos terraza y jardincillo delante, con un enorme rosal lleno de flores. De vecinos, el cuartel de artillería y sus sonidos de trompeta.

Vivíamos en el primero; en el bajo tenía el despacho mi padre, un antedespacho con un piano de pared, un arco de piedra de las murallas de Pontevedra y separada por una puerta, la caldera de carbón, el cuarto para tender, otro lleno de armarios, un aseo, un dormitorio y una gran bodega con un arcón para conservar el cerdo en sal, estanterías para la fruta, las patatas, unos barriles de vino y un cristal muy grande que contenía el hongo. Como supondréis teníamos una finca que nos mantenía y nos daba todo tipo de productos vegetales y cárnicos. Allí, se hacía el vino y el aguardiente tras la vendimia, y la matanza en casa así como los quesos.

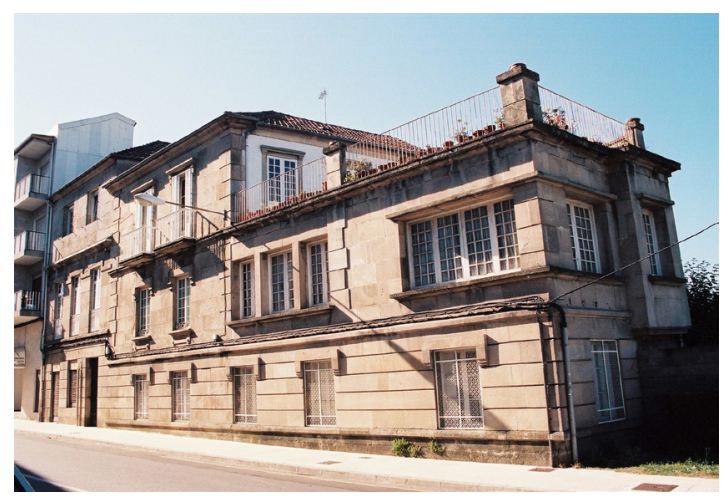

En el primer piso al entrar un gran hall con un espejo muy bonito, un arcón y una ventana ojival; a la derecha un gabinete con las paredes empapeladas, muebles antiguos, y cosas interesantes como los Castelao, Bayeu, Sobrino, Souto, Pintos y las condecoraciones...

\footnotetext{
* Nota dos editores: trátase da celebración do Día das Letras Galegas en Madrid, no marco da "V Semana Complutense de las Letras", o día 23 de maio de 2015, na Biblioteca Histórica Marqués de Valdecilla.
} 
Un pasillo conducía a un dormitorio, de frente otro dormitorio, a la derecha la escalera que llevaba a la planta baja y otra, separada, que daba a la terraza. A la izquierda un oratorio donde se dijo misa en tiempos de los abuelos con una virgen del Carmen sonriente que ahora está en la Parroquia de San José y armarios con las casullas y manteles del altar; allí reposaron los cuerpos de nuestros padres el día de su muerte antes del funeral.

Tenía una cocina grande, despensa, otros dos dormitorios, un cuarto de baño y un gran comedor presidido por un cuadro de Torres con la iglesia de Mourente y la ría, la colección de Sargadelos además de las platas típicas de la época.

El comedor y el dormitorio de mis padres tenían puertas al balcón del mar, el que daba al río, algo inolvidable por su belleza natural. Se veía también el jardín con su laberinto de mirtos, los frutales, los camelios y muchas flores. Cuando vendieron ese bonito jardín donde los canteros nos ponían los cruceros para que cogieran el musgo de la humedad de nuestras plantas, se fue parte del buen sonido que nos rodeaba, pues el martilleo de los cinceles sobre el granito era muy musical. A cambio mi padre subió el despacho al primer piso, dejó atrás la humedad del jardincillo interior, ganó luz y el no subir y bajar escaleras. En su nuevo despacho había tres mesas con diferentes temas y cuando quería descansar pasaba de una mesa a otra y así cambiaba de actividad; un pianito eléctrico y un equipo de música en las siestas, siempre escuchaba música clásica. Tenía una máquina de escribir y en casa le ayudaba Castejón, un magnífico secretario que aún vive y que le entendía muy bien la letra. En el Museo estaba de secretario García Alén que le quería muchísimo, y nosotros a él.

Escribía con bolígrafo y usaba siempre la misma agenda de bolsillo, tapas negras y semana vista. Partía las cuartillas en dos y hacía fichas para apuntar cosas que se le iban ocurriendo, que le preguntaban o le decían. En su despacho nunca le tocábamos un papel ni le movíamos nada, era su santa santorum y nuestra madre cuando él trabajaba nos pedía silencio, pocas carreras y nunca pelotas en casa. Al cabo de los años todo el edificio de mis abuelos se hizo familiar; Pili vivía abajo con su familia, Araceli en un apartamento en el segundo, y Tere con sus chicos en el tercero. Esa casa familiar fue algo muy especial para todos.

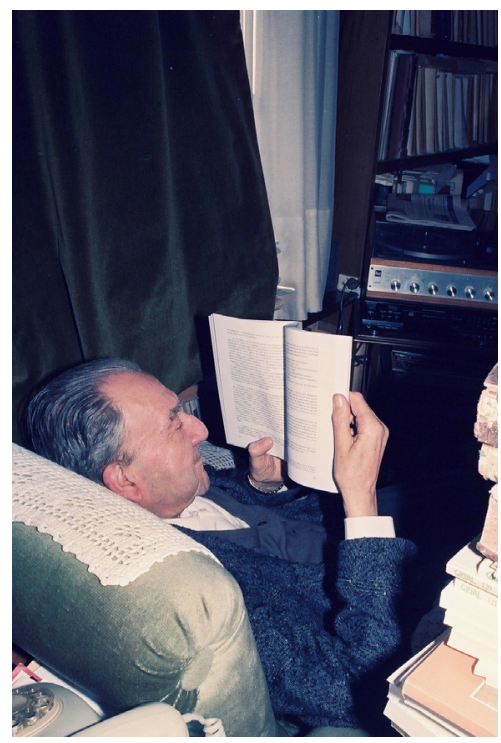

La finca "La Corba" estaba en San Blas, Salcedo, con su bosque de eucaliptos, una robleda, viñas, una era cuadrada, hórreo, mesas y bancos de piedra, un palomar, gallinas, una vaca, un cerdo, muchos frutales, una pequeña casa de piedra. Cuando le preguntaba a mi madre por qué seguíamos teniendo animales, ella me contestaba que era un círculo: la vaca come la hierba, te da el abono para el campo, te mantiene el bosque limpio, etc.

Mi madre era una persona alegre y con muy buen carácter. Se llevaban muy bien. Le acompañaba a muchos actos y en casa jugaban todas las noches al ajedrez. Como colofón os leeré unos ripios en los que mi padre habla de sus nuevas amistades, refiriéndose a mi madre con mucha gracia. En una entrevista cuando le preguntaron que quién llevaba la casa mi padre contestó: «Las cosas sencillas como la compra, los chicos, las comidas, la finca las lleva María Teresa». ¿Y las cosas importantes? «pues aún no se ha dado el caso», contestó.

La comida era siempre verdura o caldos, cocido, pescado, jureles, bacaladitos, sardinas esparradas con pimiento y cebolla, empanadas 
y postres caseros porque teníamos mucha nata y leche fresca. A mi padre, que no cocinaba, cuando entró en casa la batidora turmix, le dio por hacernos sopas de todos los colores vegetales que nos resultaban rarísimas, pero ahora están de moda.

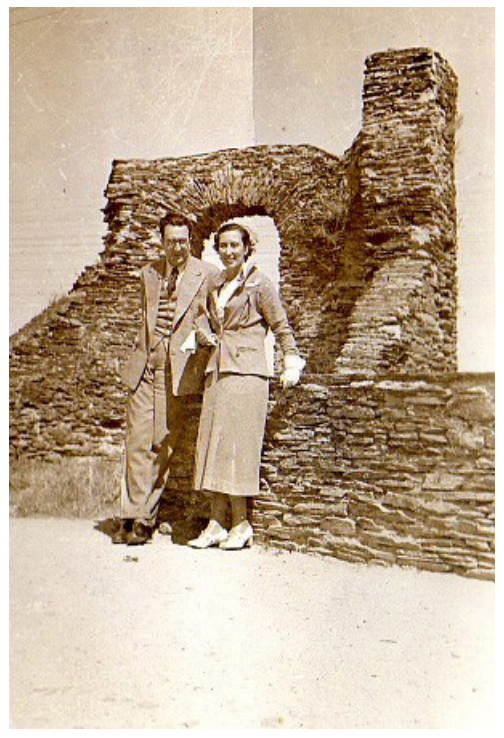

Después de comer siempre tomábamos café, una copita de aguardiente y un poco de chocolate. A esta hora solían visitarnos el médico de la familia Hurle y Antonio Iglesias Vilarelle, quien compuso "O neno ten soniño", inspirado en una canción de cuna que nos cantaba mi madre. José Fernando, mi padre, estaba un ratito y se iba a su despacho a descansar.

Muchísimas veces mi padre traía invitados de última hora, le preguntaba a mi madre si podía llevarlos y ella enseguida organizaba un menú "bueno, bonito y barato". No se agobiaba y todos le ayudábamos, era una mujer con un gran encanto.

Cuando íbamos a un restaurante y mi padre nos preguntaba "¿tú quieres esto?...» Sabíamos que eso era lo que a él le apetecía y para no pedir un plato completo siempre probaba de los nuestros. Si tomaba camarones ponía ordenadas las cáscaras y los comía con mucha rapidez. Cuando yo estaba estudiando en Madrid íbamos mucho a los Restaurantes chinos y a los alemanes. Después asistíamos a las tertulias de la Casa de Suecia o al Círculo de Bellas Artes. Muchas veces comíamos en casa de Sánchez Cantón con su hermana Hortensia, eran muy amenas las sobremesas.

El otro día, en el homenaje a Ónega coincidimos con uno que organizaba los famosos cocidos de Lalín y nos comentaba que Filgueira iba todos los años y que lo disfrutaba muchísimo. No bebía, hasta al mejor vino le echaba agua; fuera de casa pedía siempre agua de Mondariz y antes de dormir un vaso de agua con unas gotas de wiski.

Era una persona sencilla que disfrutaba con todo, con un afán de saber y de transmitir. Valle contaba que siempre supo crear equipos y Otero Pedrayo decía «ese Filgueira que todo lo puede».

Algunas cosas que mi padre no hizo: montar en bicicleta o patines, jugar a las cartas, ir de caza o pesca, conducir un coche, hacer deporte. Era un "disfrutador": le gustaba el fútbol y en el Instituto impulsó la práctica del deporte e incitó a los jóvenes a competir. Resultaba más negativo faltar a las clases de gimnasia que a cualquier otra asignatura. Así, quedó el centro muchas veces campeón. Él decía:

Me lo pasé muy bien trabajando pero renuncié siempre a las ofertas de fuera como por ejemplo a la Cátedra Cotarelo de Madrid. En el 36-37 grandes amigos exiliados me pidieron que me fuera de Galicia pero yo contesté que hacía falta en Galicia, además yo tengo una vocación docente muy fuerte y preferí enseñar a alumnos gallegos que a los de Puerto Rico. Las quince lecciones de literatura gallega que di en la universidad de Santiago me llenaron de felicidad.

Otra prueba de su amor a Galicia fue el cambio de su cátedra de Barcelona por la cátedra de Lugo.

Respecto a su escritura Villares decía que era elegante, culta. Estaban recuperando una cultura e intentaba utilizar palabras que no se utilizaban y a renglón seguido las explicaba, pues opinaba que esas palabras eran muy hermosas y patrimonialmente muy importantes, que no se debían perder. Valle decía que en las excavaciones de A Lanzada interrogaba a los paisanos para recuperar palabras. 
Con unas palabras suyas, los ripios con los que explicaba la elección de mi madre como esposa, voy a acabar sacándoos unas sonrisas. Los he recortado por su extensión para este acto; quizá queden algo deslavazados, pero espero que disfrutéis con ellos de Filgueira.

Muchas gracias a todos por acompañarnos en el Día de Filgueira Valverde.

\section{Informe en ripios \\ sobre las nuevas amistades}

Llego el momento de explicaros mi carta misteriosa apelemos al verso, por ser seria la cosa.

Por fin, senores mios, voy a oir los consejos que de antiguo me daban los niños y los viejos.

Col mi perril monástico y $\mathrm{mi}$ gesto erudito amores $y$ amorilos me importaban un pito

y era tan grave cosa pensar en casamiento que el consejo mejor era el mayor tomento.

Pero al in 1 lega el tiempo en que libros no bastan en que cuadows hastian y cuartilias aplastan,

en que un vacio enorme se siente en miestra vida $y$ en in todo a animarnos nos convida.

Y asi me liegó a mí tal tiempo extraordinario, mayo en estío por ser tan solitario.

Largas meditaciones que plantean de navo de la vocación propla el tra-cendent juego...

y al fin la decisión. fime y definitiva,

de encontrar mi pareja y vivir nueva vida.

Y de dotar a los padres respetables

de una hija polltica de moda'es amables.

y, consiguientemente, de un mubio nietecilio,

a quien dar pronto lós juguetes del barl del pasilio.

Le llevo pocoa atros y los dedos bastantes

para no parecer pareja de gigantes.

Es morena, sano el color, la boca un poeo grande, los ojos muy alegres y al andar elegante.

Nunca pierde Ia cara un dulce sonreir, pero a carcajadas no se la ve reir.

Es afable, muy fina, muy sut1l decldora, de todas cuantas vi mejor conversadora.

Es de buena familia. muy bien empareentada. de casa peincipal.pero no encopetada.

Los padres forman un pareja antigua y seforlal. y viven románticamente. rrente a la catedral.

E1 parecido de las familias es muy simpatico. es hija de médico titular y catedratico.

el padre es de Gajicia. Ia madre es de Navarra. bisabuelos maternos que vinieron de Italia... muestros hijos serian un cocktail delicioso. y sólo por eso valdría la pena hacer el oso.

y como tiene en puericultura un titulo oficial. podría aplicarla al propio persoral.

Tal es . sefores mios. Ia chica que acomoatro. y el arca donde busco el mejor patio. 